\title{
Agile Bureaucracy for Public Policy Accountability: Implementation of the Street Vendor Policy in Indonesia
}

\author{
(Agile Bureaucracy)
}

\author{
Sofjan Aripin*, Rulinawaty \\ FHISIP, Administrasi Publik \\ Universitas Terbuka \\ Banten, Tangerang Selatan, Indonesia \\ *sofjan@ecampus.ac.id, ruly@ecampus.ut.ac.id
}

\author{
Lukman Samboteng \\ FISIP, Administrasi Negara \\ Politeknik STIA Lan Makassar \\ Sulawesi Selatan, Makassar, Indonesia \\ lukmansamboteng@yahoo.co.id
}

\begin{abstract}
Public policy accountability seems to pose an everdeveloping challenge all around the globe. The increasing rate of complexity at the global scale compels bureaucracies to enhance their capabilities. In reality, however, bureaucracies become the most frequent targets of complaints from civic community organizations with respect to public policy implementations. On the other hand, they are seen as necessary multilateral, but much-in-need-of-reform, actors in global development. The main objective of this study is to build an agile bureaucracy model for public accountability in the implementation of the street vendor (PKL) policy in Indonesia. This model will observe whether agile bureaucracy management is helpful or inhibitory instead to the implementation of public policies. This study will also reveal the demanded accountability and politicization in policy actors' relationships. Data were collected by interview through focus group discussion (FGD) technique with twenty street vendor groups, with 10 to 15 members in each group. Documentation of informants who were directly involved in activities was also carried out. Data analysis processes included data reduction, data presentation, and conclusion drawing. The results of this research showed that building an agile model for the implementation of public policies helps teams with governance to generate high-quality outputs quickly. This features changes to the mindset which prioritizes clear, thorough vision over prescriptive details. This facilitates flexible leadership and organizational structures, cross-functional teams, talent ecosystems, and collaborative cultures and behaviors. Upon improvement and application to all organizations, agile breaks down functional silos, heightens transparency and accountability, and empowers employees.
\end{abstract}

Keywords-agile bureaucracy, public policy accountability, public policy implementation, street vendors

\section{INTRODUCTION}

Accountability is one of the most central concepts in the contemporary political and economic realms. Implementation of government power is legitimized by public accountability requirements [1]. Reforms in the economic and public sectors across many countries seem to be pushed by deregulation needs while still maintaining accountability. Absolute transparency and responsibility are often described as a critical precondition for accountability achievement.

Public policy accountability seems to pose an everdeveloping challenge all around the globe. The increasing rate of complexity at the global scale compels bureaucracies to enhance their capabilities. Among global governance organizers, bureaucracies become the most frequent targets of civic community organizations with respect to public policy implementations. On the other hand, they are seen as necessary multilateral, but much-in-need-of-reform, actors in global development. Bureaucracies as public policy implementers must be able to demonstrate policy accountability although this aspect of accountability is often neglected or even forgotten. Public policy accountability serves as an instrumental reinforcement that provides direction, purpose, and limit to working with someone else. Accountability is a quality of agile.

Governmental institutions have policies for agile governance and introduces novel practices and guides [2]. Agile mindset is a piece of software designed for individuals to become either better or worse. However, this is not the case when software development is seen as a robotizable activity. Agile is built upon software development as a creative activity (not of industrial purposes) for human beings (as opposed to changeable machinery tools). This leads to a high prevalence of such emerging terms of collaboration and independent organizations in the agile context [3].

Agile is highly contrasted with the waterfall method. Accountability has a strong association with agile through Scrum as it implies transparency, hard work, doing the best, responsible action, information sharing, and disclosure of the fact of success or failure. Accountability often is a boomerang 
to the government and is many a time misunderstood. It is taken for a collateral for a desired outcome, a promise of the future. Such an understanding will pose the threat of putting blame to those in charge when the predicted outcomes are not truly or fully attained. Positioning accountability in such a way will give rise to a ruling and controlling bureaucracy.

One of the public policies serving as a focus to this study is the Street Vendors Organization and Empowerment Coordination policy under Presidential Regulation No. 12 of 2012. This policy aims to empower actors of people's enterprises engaged in trade businesses in the informal sector for their enterprises' development. The booming of the number of street vendors (PKL) has impacted the esthetics, cleanliness, and functions of facilities and infrastructure in urban environments and led to congestions to road traffics, necessitating organization of street vendors (performance Report of the Street Vendor Agency on 2019).

The Statistics Indonesia (BPS) reported that there are 36.7 million non-agriculture enterprises in Indonesia. This figure increased by $20.6 \%$ from the one recorded during the 2016 economic census (26.7 million). Of the figure above, roughly $72.8 \%$ did not occupy any building. Such enterprises included those run by hawkers and street vendors, home-based enterprises, to name a few. The remaining 7.8 million occupied special buildings as premises. By location, Java Island hosted the largest number of enterprises (16.2 million). However, this island recorded a low growth rate of enterprise number of only $11.9 \%$. Following in the second place was Sumatra Island, the third Sulawesi Island, the fourth Bali and Nusa Tenggara, the fifth Kalimantan Island, and the last Maluku and Papua Islands with a total of 500 thousand enterprises. Yet these regions recorded the highest growth rate of enterprise types in Indonesia $(51.7 \%)$. The rise in the numbers of street vendors and hawkers Indonesia is facing poses a fairly serious challenge, making it challenging to organize and empower street vendors. If no agile bureaucracy is in place to counter this rise, policy implementations will only face failures. In addition, sprawls in major cities in terms of urban esthetics will occur, and no street vendor empowerment will be realized.

The phenomenon above shows the complexity of street vendor organization and empowerment policy implementation. This policy involves a variety of stakeholders with varying responsibilities and tasks, leading to frequent overlaps of the policy and the target group, that is street vendors. On the other hand, the policy implementer (governmental bureaucracy) is required to execute the policy in effective, efficient, and publicly accountable manners to the community [4].

Some relevant previous research indicated this study's position relative to the other research. Some of the said research studies are as follows:

- Rulinawaty et al. [5]. Leading Agile Organization: Can Indonesian Bureaucracy Become Agile? This research successfully found that Indonesian public bureaucracy is still weak. The research results are expected to have an impact on the leading public bureaucracy to build new qualifications and capacities to create policy formulation patterns, policy formulation capacities, and even training education models to create agile policies.

- Rulinawaty et al. [6]. Crafting Agile Bureaucracy: Transforming Work Ethics of Civil Servants and Organizational Culture of Bureaucracy in Indonesia. The results showed that the agile methodology is the only method the government and private organizations can use to keep up with changes in the market environment. Bureaucracies must turn agile. However, evidence showed that community organizations are unable to evolve to match technological changes. Organizational structures and cultures are one of the reasons why community organizations in Indonesia find it difficult to become agile.

- Linda Susan Holbeche [2]. Shifts in Organizational Culture When Implementing Agility. The results showed that attempts to scale up agility to an enterprise level generally meet a little success typically due to cultural barriers, with conventional leadership approaches, linear thinking, and mechanistic change management being particular stumbling blocks. It is often assumed that, as people engage and start using the agile methodology, they will feel committed to sustain the benefits of agility, including innovation. However, tackling only one aspect of cultural change is unlikely to produce a lasting value.

- Amy Tsui. Performance Monitoring and Accountability: The Agile Project's Protocol, Record and Experience. The Performance Monitoring and Accountability 2020 (PMA2020) project implemented a multi-country sub-project called PMA Agile, a system of continuous data collection for a probability sample of urban public and private health facilities and their clients that began November 2017 and concluded December 2019. The objective was to monitor the supply, quality, and consumption of family planning services. In total, across 14 urban settings, nearly 2,300 health facilities were surveyed three to six times in two years, and a total sample of 48,610 female and male clients of childbearing age were interviewed in Burkina Faso, Democratic Republic of Congo, India, Kenya, Niger, and Nigeria.

Regarding the above-described, this study focuses on the perspective on agile bureaucracy for public policy accountability: the implementation of the street vendor policy in Indonesia. This perspective is explored for the purpose of organizing and empowering street vendors in the implementation of public services and public policies. The main objective of this research is to build an agile bureaucracy model for public accountability in the implementation of the street vendor policy in Indonesia. This model will observe agile bureaucracy management as to whether it is helpful or inhibitory to the implementation of public policies. This study 
will also reveal the demanded accountability and politicization in policy actors' relationships.

\section{LITERATURE REVIEW}

\section{A. Agile Bureaucracy and Accountability}

Agile is highly contrasted with the waterfall method, in which case implementation must go through project phases in an order [7]. Agile bureaucracy as a tool of accountability. Accountability refers to a state's responsibility, covering expectation, ability, and willingness to share not only results but also beyond. It refers to the various actions to be taken and decisions to be made, and it explains why an action is implemented and why it is not, what is the rationale behind the implementation or non-implementation, and so forth. In fact, accountability is less related to the actual outcomes than to sharing, explaining, and justifying the actions taken or not taken, the decisions made or not made, and all relevant considerations toward the actual outcomes.

Agile bureaucracy must support the success of public policies both in terms of formulation and especially in terms of implementation. Agile bureaucracy is responsible for demonstration of progression toward agility. The government helps prepare all employees to become agile through vision and transparency in the performance of teamwork tasks. This shows individual accountability to the team and team accountability to the sprint commitment.

Bureaucracy accountability over the time is linked to a value or part of organizational culture. Some public organizations tend to be low in accountability, too soft, and too inclined toward micro-management. Agile work teams are not necessarily immune to accountability. Agile accountability is part of a healthy culture and becomes a value and responsibility at every level: organization, group, and individual. At the organization level, leadership must work to create an accountable culture and demonstrate that the organization expects the employees to perceive themselves as responsible and intolerant to any behaviors, systems, and structures which are not congruent with the organization's values.

Bureaucracy is serving leaders at Scrum Master. The Scrum Masters openly acknowledge their mistakes and are responsible to others for their roles should the teams face a failure. On the part of the agile team members, they are responsible not only to one another but also to what they are doing. They also ask the responsibility of one another for the work agreement their teams entered. In the Scrum context, reversed accountability form refers to the reverse of the following Scrum principles: cross-functional collaborations, use of collective intelligence, bottom-up knowledge creation, and common purpose.

Accountability is gravely important in public policies. Erroneous implementations in various contexts do not undermine this level of importance. Eliminating and averting accountability also have detrimental effects on the organization, such is the case when there is a lack in vision, focus, direction, option, or discussion and when there is doubt at work. Agile Scrum estimates a clear accountability for every Scrum role. Although accountability is assigned per point, it is needed. For instance, the development team is responsible for creating increments that can be removed or changed according to the internal and external environmental changes, the policy implementers are responsible for maximizing the job value, and the Scrum Master is responsible for Scrum understanding and implementation.

Agile becomes a global organizational trend to improve organizations' market capitalization. Agile organizations demonstrate how agile thoughts are applied to every aspect such as innovation. An agile bureaucracy will display its work accountability. Accountability will become a culture when a work team acts with a high level of accountability other teams will emulate. Collaboration with and assistance from others are required to fulfill accountability. An agile bureaucracy has a shared responsibility for the organization, community, and the wider ecosystem.

\section{B. Accountability from the Public Policy Implementation Perspective}

In a public policy cycle, policy implementation becomes one of the most crucial things in a policy process for generating a policy performance. A public policy is said accountable if the inputs, processes, outputs, and outcomes meet the team's policy target and if the policy goals are achieved. Unfortunately, however, public policies over the time are good only at the conceptual level but failing in the implementation [8]. Of course, this is caused by the politics-administration dichotomy which makes public policies no longer as simple as when implemented in the field, in which case public policy discretion is needed [9]. Moreover, public governance perspectives must also be implemented, that is through the involvement of the public, private, and community sectors to avoid multiple interpretations of the policies' purposes by grassroots implementers.

Accountability differences in the policy implementation throughout the course of the implementation study can be interpreted differently between three generations [10]. In the first generation, the purposes and success of a policy will be varied in extent when replicated in varying areas. The policy accountability in this generation cannot be used as a public policy accountability work model, but its strengths will give birth to multiple accountability options which are designed by the government. In the second generation, the public policy accountability model has allowed replication in various locations as development in this generation exhibits similarities in the predictor variables, policy forms and contents, organizations, resources, talents [11], and communication relationships. Meanwhile, the third generation in the public policy implementation study develops to refine the two preceding generations with an integration of top-down and bottom-up research studies in a single framework. Public policy accountability in this generation is also replicable in different areas with a consideration of the indicators, variables, and factors which can influence public policy implementations. 


\section{Accountability from the Public Policy Implementation Perspective.}

Accountability has been defined as "an obligation to present an account of and answer for the execution of responsibilities to those who entrusted those responsibilities" $[12,13]$. Accountability has a certain right to ask the other's responsibility [14]. The interpretive model for accountability purposes in the public administration is deeply rooted in the mechanism related to representatives and refers to public management delegation based on the mandate of the general elections, the legislative body. The political administration elections for the nominated candidates represent their elections for a variety of interests.

Accountability management manages based on delegation from the public, in which case bureaucracy not only runs and wields power to achieve collective purposes and interests but also be responsible for their actions to various stakeholders. From the public administrative perspective, accountability is built in the relationship between representative elective entities (the House of Representatives and the government) and technical-executive elective entities (local and municipality governments), where the government bureaucracy manages the power entrusted to them by the community according to the government talents and resources. From another perspective, it is established in the relationship between administrators, elected representatives, and voting citizens to verify compliance with the general elections' decisions.

Accountability is the impact of public goods distribution, public services delivery, and the rules set. Accountability application in the public sector needs an explicit rule and principle system which underlines the organization's obligation to be responsible to all stakeholders for the mandate given to them for the organization's goals achievement [15]. Accountability in an agile bureaucracy needs a set of information channels which are reliable, understandable, accessible, and able to reach across multiple sectors and geographical barriers. This reflects bureaucracy's responsibility to provide information and to establish internal and external communications. Accountability essentially is a way in which power controls over managerial outputs and is exerted to parties related to the activity $[16,17]$. It can be said, then, that the quality and level of accountability are correlated with information methods. An agile bureaucracy is able to activate complex reporting systems and is centred on unique data systems and value documentation, ensuring managerial, administrative, and institutional reinforcements.

\section{RESEARCH METHODS}

\section{A. Location}

This research was conducted in Makassar City under the consideration that Makassar is a metropolitan city that houses more street vendors than do other cities in South Sulawesi Province. In addition, the increasing number of street vendors every year in the city leaves complex problems such as traffic chaos and damaged urban esthetics. As reported by the Office of Industry and Trade of Makassar City in 2019, the number of street vendors in Makassar City over the last three years had increased significantly. This research took five of the existing 14 districts in Makassar City-Tamalanrea, Mariso, Wajo, Biringkanaya, and Makassar Districts - as sample. The five sample districts exhibited the street vendor characteristics as described above.

\section{B. Research Designs and Strategies}

This research used a qualitative design and a case study research strategy. This research design aimed to reveal the street vendor policy implementation based on the context. In this case study, the research strategy employed was of the explanatory type [18].

\section{Informants}

The informants in this research were determined purposively. The informants were those who were considered as competent in relation to public policy implementation in the community empowerment field in Makassar City. Such a manner of informant determination was exercised by experts (or in this case the researchers) for certain purposes or certain situations stated by Miles et al., The informants in this research were individuals and institutions who/which served as lowlevel bureaucracies, including a) employees in the Community and Village Empowerment Section, b) the Community and Village Empowerment Section, c) the Governance Section, d) the Peace and Order Section, e) the Economics and Development Section, f) empowerment cadres, g) the Community Empowerment Agency (LPM), and h) street vendors.

\section{Data Collection Technique}

In this research the data collection techniques used included observation, interview (questionnaire), in-depth interview, focus group discussion, and documentation. Observation was particularly performed on tangible objects such as pre- and post-harvest processing activities. In-depth interview was carried out on the informants abovementioned. Lastly, documentation was conducted by collecting documents in the form of laws and regulations, journal articles, and research findings related to this research.

\section{E. Data Analysis}

The data processing technique was implemented through data reduction, data presentation, and conclusion drawing/verification [19]. Data analysis used pattern matching technique and time series analysis.

\section{RESULTS AND DISCUSSION}

\section{A. Agile in the Indonesian Bureaucracy Domain}

Agile is not the most potent weapon. There is no one-sizefits-all model that can be easily transferable from the private to the public sector either. No one should underestimate the 
challenges to be faced by the government in adopting agile ways of working [20]. Government organizations have generally been designed to develop services and execute programs by the waterfall approach. However, the diverse policy targets and purposes in the public sector create complexity and conflicts, making it difficult to set a goal. Altering the governance, budgeting, and funding models long established can be extremely challenging. Yet, agile demands other kinds of changes too. Measurement and accountability frameworks need to be redesigned, and internal and crossinstitutional silos need to be broken down. Organizational cultures, leadership styles, and professional mindsets should be reoriented [21].

Irrespective of the challenges above, the government's interest in agile is continuously strengthening. Despite the differing wordings, some main fields must be handled in every transformation. This will shape the following agile operational model:

- Purpose, Strategy, and Priority. Agreement on this is critical before the organization allocates resources appropriately and starts to build the infrastructure needed by the agile approach. Ensuring that everyone is clear about the organization's purposes and strategies and understands why and how the organizations must change are important to allow autonomy at all levels.

- Governance and Funding. The organization must shift to a more flexible capacity-based funding approach with periodical initiative reevaluation to make sure that it runs on the right track and deserves continuous funding.

- Structure. A better organization with a wider range of power and clearer accountability and employee empowerment program ownership to take responsibility for decision-making and problem-solving. Line managers act as coaches and facilitators rather than bosses.

- Process. Cross-institutional coordination, crossfunctional teams, and strong cooperation with citizens are critical for flexible, multidisciplinary ways of working.

- Culture and Behavior. The core of agile transformation is cultural and behavioral changes. Agile prioritizes autonomy at all levels and empowers teams to experiment with alternative solutions to problems. However, autonomy may turn into chaos unless the teams at all levels have clear purposes and strategies. This will depend on strong leadership and clear, frequent internal and external communications.

- Leadership and Talent. Other than recruiting and promoting the best talents, the organization must base appreciation on outcome and colleague feedback with a focus on development of expertise and new career paths - a practice yet to be implemented broadly in the public sector. Leaders need a comprehensive understanding of the missions, purposes, and principles underlying a transformation to make sure that the teams at all levels clearly know the "why" - the strategies and purposes of the organization. Then they must remove and leave behind the traditional order-and-control model and allow the teams to find out the "how."

- Measurement Framework. To appraise the progress toward a goal, data analytics must be applied more widely across the organization. Transparency in the measurement framework is critical and can be achieved by means of digital and analytic tools to assess and track improvements empirically. The point is that data must be vast available throughout the organization.

- Technological Support. Agile requires a transition from a heavier mainframe to a more modular system to give teams greater ownership of their end-to-end processes. The important elements contained in technological use include the following: the various devices used to manage workflows from ideas to development and to the hands of the users; continuous delivery, automatic testing, and DevOps (which integrates software development and operation); and a defined technological architecture which identifies important data for the organization and the system that creates and manages it.

As with any other big-scale change efforts, chances are resistance will occur along the way. Transition toward agility, for example, creates uncertainties among many employees. Hence, it becomes important for leaders to build a clear understanding of every individual's role in a new organizational structure [2]. Agility is a highly transparent way of working, which to some may feel uncomfortable. As it carries a fundamental change to the way in which citizens are provided with services, effective change management becomes of much importance.

Starting with modeling in one or two areas can build trust, allowing others to see the benefits and paving a way to adoption and launch throughout the organization. Conversation on the application model and how to conceive a pilot project toward a success is also crucial. Yet, although various tools, processes, and methodologies can be used to support agilityfrom collaboration software to daily stand-ups and retrospective meetings - an appropriate change in the mindset is also needed [22]. See figure 1 below. 


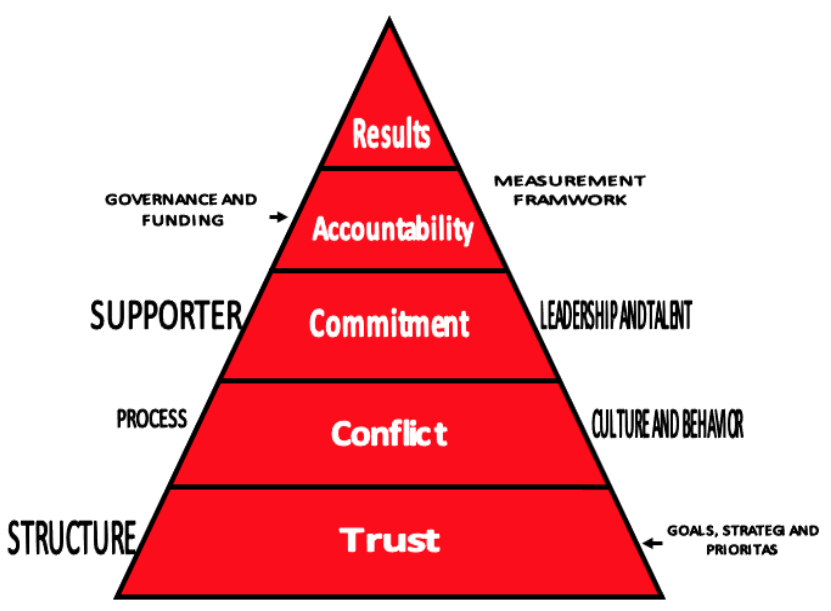

Fig. 1. Agile public policy accountability model.

\section{B. Agile Bureaucracy for Public Policy Accountability}

Emerging as a software engineering approach in the early 2000 s, agile rapidly rose as a new organizational paradigm. Using agile methodologies, multidisciplinary teams work in fast, repeated sprints. The majority of governments have most likely adopted several agile forms when implementing technological projects, and some organizations in the public sector used them in digital services delivery. The most recent is ideas of how to implement agile ways of working on a large scale throughout companies. Private sectors have implemented those and enjoyed significant benefits. Public-sector organizations such as the World Bank have also started to adopt agile on a large scale [8].

The public sector is also facing unique challenges in the need to operate within the legislative framework and in the nature and time of political decision-making. It must work with a small manpower flexibility. Included in such small flexibility is employment termination issues and rigid job description, level, and remuneration. Besides, unlike any other organizations, the government must constantly consider the voters. However, organizations that move toward agility can provide programs and services of higher qualities more efficiently and with smaller risks. And by allowing the employees a greater autonomy - along with clear guides and leadership toward their goals and strategies - these organizations will be able to let go of large productivity dividends which currently are inactive among public-sector manpower [23].

Agile has also been implemented in the public sector. For example, after the World Bank launched smart ways to work throughout the organization, the impact of the global development program increased, and so did the employee involvement [24]. This could be realized not by changing individual projects or departments but by moving the greater part of the, or even the entire, organization into a new way of working - one which provides an effective way to deal with a wide variety of deeply rooted problems. In policy regulation, agility can help set clear policy goals needed to prioritize and arrange works. It can be used to perform test-and-learn experiments to determine which way is the best for the purpose of achieving desired outcomes, which oftentimes enables more interdepartmental collaborations. It also has wide applications in the service design and continuous improvement which are more customer-centered, efficient, and quicker in introduction. Potential benefits for all stakeholders are quite large, but agile implementations are not for those who are weak-hearted. The structures, processes, behaviors, and cultures developing within the last few decades are hard to change.

On the other hand, policy makers are often disappointed with the policy outcomes when the policies are implemented. What they expect are a far cry from the reality. Meanwhile, community members who demand high-quality services often find the government a disappointment in many respects, starting from the solutions offered to the existing problems and the services complexity to the impersonality of the relationships with government actors. Policies more often face failures, causing the government to lose the community's trust. Failed projects, wastages, and inefficiencies are often resulted. In the bureaucracy environment, hierarchy is a must. With the wider gap between expectations and what actually are achieved, the government should change their operation models in the public sector in a fundamental way. The key to this is the practice which collectively is known as agile [25].

\section{Challenges in Adopting Agile in Indonesia Bureaucracy}

Agile is designed to maximize team opportunities in providing reliable products to meet users' demands and at the same time to minimize failure risks due to environmental changes and limited testing. In an agile process, a multidisciplinary team breaks down large products or projects into smaller, discrete features and gives away these features one by one when testing the functionality and utility of the whole project. In the government bureaucracy context, instead of executing every program, or policy, step separately, bureaucracy works starting from planning, designing, and implementing, to testing/reviewing respectively of the policy products directly tested on the public. In the street vendor policy implementation cycle, testing is only performed by moving the locations of the street vendors' operations without performing any comprehensive test. This increases the failure potential if the policy message is poorly understood throughout the process. In the street vendor policy implementation in Indonesia, this research discovered the chief challenges in transferring agile into governance, especially in the field implementation of all governmental organizations. These challenges are as follows:

1) Agile vs. Bureaucratic hierarchy: Division leaders not taking responsibility for the actions taken by their agile work teams is considered normal in government bureaucracy. They tend to avoid risks posed by the new innovation models developed by the agile work teams. Innovations are avoided to avert failures to the public policies. Agile will never be 
attractive to hierarchical organizations. Agile bureaucracies cannot rely on the standard operation procedures that have been set. As a result, the actions of an agile bureaucracy are directly aimed at the administrative-legalistic culture. Hierarchical bureaucracies deem that agility is in conflict with the administrative law, necessitating evaluation of agile implementations by case. Most hierarchical bureaucracies regard agility as a model or trend that will change [23,26]

2) Agile bureaucracy leadership: Leading an agile organization is unlike leading a conventional one. An agile leader spends less time to observe the works of his/her subordinates [27]. He/she adapts organizational strategies by transforming into an adaptive organization, leading agile teams, focusing on customers, guiding individuals, and training teams into becoming agile. He/she serves as a model to his/her subordinates by changing one's behaviors, rearranging daily routines, and developing new skills [2].

An agile leader needs decision-making based on agreement and acceptance with a trial-and-error approach. He/she is not visible in sub-divisions. Decisions are in the hands of nonleaders, necessitating protection for agile work teams against other external political influences that will affect the teams' works. Agile leadership prioritizes subordinates, helping them to grow and achieve success in the organization and allowing them to create value for the community. Agile bureaucracies should emphasize servant leadership instead of services for leaders.

Policies must focus on end users (street-level bureaucracies). Therefore, public policies must be designed to understand user behaviors in detail and to meet street vendors' needs. Street vendor policy implementation should focus on the delivery of tested products through documentation and communication. But it is worth noting that excessive documentation/rule preparation will only inhibit bureaucracies to adapt to changes in the field. In terms of communication pattern, in the policy implementation, informal, quick, orderly communication rather than formal, rigid communication is needed. Informal bureaucracy communication with street vendors will help deal with policy gaps (communication needs no lengthy memos and documents). In the evaluation stage, rapid feedback should be made to understand the changes that take place in the field. Changes to plans become normal in agile bureaucracies. See table 1 below.
TABLE I. AgILE BUREAUCRACY POLICY PRINCIPLES

\begin{tabular}{|l|l|l|}
\hline \multicolumn{1}{|c|}{$\begin{array}{c}\text { Public Policy } \\
\text { Processes }\end{array}$} & \multicolumn{1}{|c|}{$\begin{array}{c}\text { Traditional } \\
\text { Bureaucratic } \\
\text { Principles }\end{array}$} & \multicolumn{1}{c|}{$\begin{array}{c}\text { Agile Bureaucratic } \\
\text { Principles }\end{array}$} \\
\hline Formulation & Focus on the rules set & $\begin{array}{l}\text { Focus on customers rather } \\
\text { than contract negotiations }\end{array}$ \\
\hline Design & $\begin{array}{l}\text { Priority given to } \\
\text { budget/ inputs }\end{array}$ & $\begin{array}{l}\text { Priority given to functional } \\
\text { human resources over } \\
\text { documentation }\end{array}$ \\
\hline Implementation & $\begin{array}{l}\text { Policy implementation } \\
\text { with avoidance of } \\
\text { discretion }\end{array}$ & $\begin{array}{l}\text { Encouragement individual interaction } \\
\text { through not only process } \\
\text { but also informal } \\
\text { communication }\end{array}$ \\
\hline Evaluation & $\begin{array}{l}\text { Must be in accordance } \\
\text { with the plans } \\
\text { established }\end{array}$ & $\begin{array}{l}\text { Planning changes instead of } \\
\text { following through plans }\end{array}$ \\
\hline
\end{tabular}

From the analysis results above, the following agile management steps are designed to help with accountable public policy implementation.

- Step 1: Form multidisciplinary teams that consist of not only policy makers but also policy-implementers.

- Step 2: Determine the various policy 'users' and think about the behaviors and characteristics that divide into useful resources. Conduct interview with users and/or observe user behaviors when users interact with a policy or program to derive an understanding of the user experience and points of friction. Users are not only institutions which implement the policy, but also endusers which/who are affected by the policy (e.g. businesses and citizens). Focus on behaviors and demand, rather than only on what is wanted by users. Journey mapping is a useful practice to understand experience with the policy. Managers or leaders in the product division are tasked with advocating users' needs in the bureaucracy.

- Step 3: Analyze problems as in any policy process. Split problems into policy formulation which will be attractive to the users and which discusses "user experience" or certain matters

- Step 4: Divide policy features into a number of constituents to form "sprints" or sets of works that produce performance. Frequently meet up as a team (often termed daily "scrum") to discuss progress, the next step, and any internal obstacles or challenges immediately. Choose a scrum master (someone who presides over the meetings) to ensure that the challenges are dealt with.

- Step 5: Develop a prototype and test the policy performance with the primary users and stakeholders. You may test a number of policy ideas at once to understand the advantages and disadvantages of each The test should not necessarily be too scientific or strict; the main purpose is to test your assumptions in the rea world. Let the most important users know about the 
policy and understand its impacts on their operations and behaviors.

- Step 6: Assemble lessons learnt as an end product while allocating time to reflect on and refine your process throughout the sprint "retrospective." One of the simplest formats is to ask every team member about what must be started, terminated, or carried forward by the team in the next sprint.

- Step 7: Collect successful policy features in an initial product that is set for a release. Incorporate such features in the product which has received routine feedback from the users. Keep testing and adjusting the policy, or its implementation, even after the issuance. Learning should never end.

3) Inhibitions to agile for public policy accountability: Becoming an agile bureaucracy is not easy as an agile bureaucracy more often redesigns every element of its performance like roles and decisions, recruitment system, talent management, and so forth. It is not a rarity too for the organization's chart to change with the alterations in the organizational environment, such as the alterations in planning, budgeting, and review. The purpose for an organization to turn agile is to help the customers achieve their respective goals [28].

In the street vendor policy implementation, there will be many situations in which agile management is to be applied. In some cases, stakeholders who are involved in the street vendor policy will tend to have limited tolerance to adaptive environments, making it hard to implement agile principles. Stakeholders are of the view that the policy design should not be altered in the field. They demand stability. However, to become agile, the plans developed may be subject to changes according to the conditions in the field. The government, on the other hand, assigns bureaucracies to operate interorganizationally with regard to the street vendor policy implementation while still remaining in the command line with a clear hierarchy and border line, limiting the opportunity to establish cross-sectorial teams that may be comprised of policy experts, implementers, analysts, other stakeholders, and the community.

At the budgeting level, there is rigidity in the budgeting and planning cycle, which will limit the exploration process. It will be difficult for the government to extract and allocate resources during the policy implementation. To make the policy accountable in the budgeting process, stakeholders must have a specific understanding of the right solutions, processes, and schedules in the street vendor policy development conducted by the bureaucracy. This will include understanding the users, cooperating with the implementers, engaging in trials and errors through plan changes and implementations to produce a more adaptive policy. By emphasizing agility in the street vendor policy implementation, policy performance will be realized. To become an agile bureaucracy, agile thoughts should be implemented in work activities such as making innovations like service agility, back-office agility, agility management, and a process of transformation into agility.

Agile operates at the empirical and philosophical levels, saying that all hypotheses must be tested with empirical proofs [29]. It is extremely difficult for a bureaucracy to become agile as it is burdened by structures, rules, and bureaucratic processes. Agils is concerned with "how an organization works holistically - in its operational model, which significantly is more important than its formal structure." Agility is more than just a set of initiatives. "An agile transition is a continuous improvement process rather than a project with a due date. Agility sets free of innovative spirits which are paralyzed by numerous organizations."

\section{CONCLUSION}

Digital technologies have a transformative impact on the way people consume services. Applications, chatbots, and virtual assistants allow them to access services anywhere and anytime. Since these technologies drive new consumer behaviors across all industries, citizens' expectations about public services also change, to which many governments respond by investing into digital abilities. Artificial intelligence, machine learning, and predictive algorithms enable dramatic improvements in policy analysis and services delivery. However, although technologies are potent tools, they can still be paralyzed by legacy structures, cultures, and ways of working. In the public sector, institutions - and even internal functions - tend to be reserved, and the leaders are given incentives to focus on their own vertically organized and even sometimes competitive domains.

Agile helps teams arrange to produce outputs of high qualities rapidly. This involves a mindset which prioritizes a clear, holistic vision over prescriptive details. It facilitates flexible leadership and organizational structures, crossfunctional teams, talent ecosystems, and collaborative cultures and behaviors. When improved and implemented in the entire company, it breaks down functional silos, improves transparency and accountability, and empowers employees.

Agile uses the repeated "minimally feasible product" methodology, where product and service features are developed adequately for the first users to understand the concept and offer feedback. The feedback informs the next iterations, in which case the products or services are shared with a great number of users and even greater until they are used on a large scale.

This approach generates a faster, more effective product and program design than does the traditional "waterfall" methodology. In the waterfall methodology, separate teams design and assemble a product or service in successions. Every team must wait the previous team completing its job before continuing where the previous team left. Besides being slower than the agile approach, the waterfall methodology carries a misunderstanding risk throughout the implementation, which requires reparations. In contrast, the continuous testing and literacy processes in the agile approach not only improve the 
product or service but also reduce the risk of implementation failure. The fact is this research showed that an agile way of working reduces this risk by a half.

\section{REFERENCES}

[1] P. Virtanen, "Do accountabilities change when public organisations transform to service systems: A new conceptual approach", Financial Accountability and Management, vol. 34, no. 2, pp. 166-180, 2018.

[2] L.S. Holbeche, "Shifts in Organizational Culture When Implementing Agility", Journal of Creating Value, vol. 5, no. 2, pp. 124-138, 2019.

[3] W. Ahmed and M.Z. Rashdi, "Understanding the influence of lean and agile strategies on creating firms' supply chain risk management capabilities", Competitiveness Review, 2020.

[4] R. Kasmad, "Democratic Model of Public Policy Accountability. Case Study on Implementation of Street Vendors Empowerment Policy in Makassar City," Studi Pemerintahan, vol. 6, no. 2, pp. 1-17, 2015.

[5] Rulinawaty, "CRAFTING AGILE BUREAUCRACY: Transforming Work Ethic of Civil Servant and Organization Culture Bureaucracy in Indonesia," International Journal of Innovation, Creativity and change, 2020.

[6] Rulinawaty, S. Arifin, and L. Samboteng, "LEADING AGILE ORGANIZATION Can Indonesian Bureaucracy become agile?", International Research Association for Talent Development and Exellence, vol. 12, no. 1, 2020.

[7] I. Mergel, S. Ganapati, and A.B. Whitford, "Agile: A New Way of Governing”, Public Administration Review, pp. 1-5, 2020.

[8] P. Sabatier and D. Mazmania, "Sabatier_et_al-1980Policy Studies Journal," [online]. Retrieved from https://s3.amazonaws.com/academia.edu.documents/33366842/Impleme ntation.pdf?AWSAccessKeyId=AKIAIWOWYYGZ2Y53UL3A\&Expir es $=1539806052 \&$ Signature $=$ oM8Z7rAKnCJbmLcCwuHUnlN9CxM\%3 D\&response-content-disposition $=$ inline $\% 3 \mathrm{~B}$ filename\%3DCONCEPTUAL_FRAMEWORK_THE_IMPLEMEN

[9] R. Kasmad, Alwi and L. Tamba, "Discretion Dilemma of Street-Level Bureaucracy in Implementation of the Street Vendors Empowerment Policy in Makassar City, Indonesia," American Journal of Humanities and Social Sciences Research (AJHSSR), vol. 2, no. 8, pp. 106-115, 2018 .

[10] L.J. O’Toole Jr., "Research on Policy Implementation: Assessment and Prospects", Journal of Public Administration Research and Theory, vol. 10, no. 2, pp. 263-288, 2000.

[11] L. Samboteng, "Talent management of state civil officers (ASN), bureaucratic digitalization era in Indonesia", vol. 41, no. 31 , pp. $157-$ $169,2020$.
[12] K. Jarrett, "YouTube: Online video and participatory culture", Continuum, 2010

[13] B. Jenkins and A. Gray, "Codes of Accountability in the New Public Sector", Accounting, Auditing \& Accountability Journal, vol. 6, no. 3 pp. 52-67, 1993.

[14] J. Broadbent, M. Dietrich, and R. Laughlin, "The development of principal-agent, contracting and accountability relationships in the public sector: Conceptual and cultural problems", Critical Perspectives on Accounting, vol. 7, no. 3, pp. 259-284, 1996.

[15] K. Chaharbaghi, "The audit dilemma in public services", International Journal of Critical Accounting, vol. 3, no. 1, p. 18, 2015.

[16] A. Schedler, "Conceptualizing Accountability", in The Self-Restraining State: Power and Accountability in New Democracies, 1999.

[17] D. Greiling and B. Grüb, "Towards citizen accountability of local public enterprises", Annals of Public and Cooperative Economics, vol. 86, no. 4, pp. 641-655, 2015.

[18] R.K. Yin, "Interorganizational Partnerships in Local Job Creation and Job Training Efforts: Six Case Studies," Final Report, 1989.

[19] M.B. Miles and A.M. Huberman, Analisis data kualitatif. 1992.

[20] A.M. Carvalho, "Operational excellence, organisational culture and agility: the missing link?", Total Quality Management and Business Excellence, vol. 30, no. (13-14), pp. 1495-1514, 2019.

[21] E. Rebentisch, "Defining agile culture using topic modelling", Proceedings of International Design Conference, DESIGN, vol. 5, pp. 2111-2120, 2018.

[22] O. Marnet, "Explaining governance failure: accountability spaces inbetween and bias", International Journal of Critical Accounting, vol. 6, no. 4, p. 315, 2015.

[23] C.A. H. and D.L. M., "Agile feedback drives accountability and sustained behavior change", Strategic HR Review. Emerald Publishing Limited, vol. 17, no. 6, pp. 295-302, 2018.

[24] J. Birkinshaw, "What to expect from agile", MIT Sloan Management Review, vol. 59, no. 2, pp. 39-42, 2018.

[25] M. Janssen and H. van der Voort, "Agile and adaptive governance in crisis response: Lessons from the COVID-19 pandemic", International Journal of Information Management. Elsevier, (June), p. 102180, 2020.

[26] J. Piatak, Z. Mohr, and S. Leland, "Bureaucratic accountability in thirdparty governance: Experimental evidence of blame attribution during times of budgetary crisis", Public Administration, vol. 95, no. 4, pp. 976-989, 2017.

[27] S. Denning, "Succeeding in an increasingly Agile world", Strategy and Leadership, vol. 46, no. 3, pp. 3-9, 2018

[28] J. Parcell and S.H. Holden, "Agile policy development for digital government: An exploratory case study", ACM International Conference Proceeding Series, pp. 11-17, 2013.

[29] Y. Doz, "Working Paper Series Escaping the " S - Curve" - is the " Agile "Organization the Answer ?", 2019. 